\title{
Antioxidant Activity and Phytochemical Identification of Annona Squamosa Leaves Methanolic Extracts
}

\section{Mustanir $^{1, *}$, Nurdin' ${ }^{1}$, Binawati Ginting ${ }^{1}$ \\ Mustanir ${ }^{1 *}$, Nurdin', Binawati Ginting ${ }^{1}$ \\ 'Department of Chemistry, Faculty of Mathematics and Natural Sciences, Universitas Syiah Kuala, Banda Aceh, INDONESIA. \\ Correspondence \\ Mustanir \\ Department of Chemistry, Faculty of \\ ABSTRACT \\ The antioxidant activity of Annona squamosa (A. squamosa) leaf was carried out using methanol extract and fractionated extract namely $n$-hexane, ethyl acetate and residue. The antioxidant activity of methanol extract and fractionated was performed using the 1-diphenyl-2-Pycrilhydrazil (DPPH) method. The antioxidant activity test of methanol extract and fractionated $n$-hexane, ethyl acetate and residue yielded $I_{50}$ of $6.87,169.99,31.55$ and $44.75 \mathrm{ppm}$. The ethyl acetate fraction extract with $I_{50} 31.55 \mathrm{ppm}$ was performed by column chromatography using silica gel $\mathrm{G}_{60}$ as the stationary phase and n-hexane: ethyl acetate as the mobile phase. The results of column chromatography obtained 181 fractions and were combined based on the stain pattern into 4 subfractions. Antioxidant test of each subfraction showed that the ASE 3 subfraction had the strongest antioxidant activity. Furthermore, the subfraction was analyzed using Gas Chromatography Mass Spectrometry (GC-MS). According, GC-MS data analysis showed that the third subfraction contained 19 phytochemical compounds, where 3 compounds having the highest concentration, namely 4,4'-((p-Phenylene)diisopropylidene) diphenol, dodecanoic acid, methyl ester and phthalic acid, isobutyl 2-methylpent-3-yl ester. \\ Key words: Annona squamosa, Plant extract, Antioxidant activity, GC-MS.} Mathematics and Natural Sciences,

Universitas Syiah Kuala, Banda Aceh, INDONESIA.

E-mail: mustanir@unsyiah.ac.id

History

- Submission Date: 08-10-2021;

- Review completed: 29-10-2021;

- Accepted Date: 10-11-2021.

DOI : 10.5530/pj.2021.13.225

Article Available online

http://www.phcogj.com/v13/i6

Copyright

(C) 2021 Phcogj.Com. This is an openaccess article distributed under the terms of the Creative Commons Attribution 4.0 International license.

\section{INTRODUCTION}

For the past few decades, several health issues in Indonesia was related to the diseases due to free-radicals originated from the residual of body metabolism and from foods, UV exposure and tobacco smoke., ${ }^{1,2}$ In order to neutralize the increment in free radicals in body therefore antioxidant was used to prevent the build up concentration. If the imbalance between total free-radicals with antioxidant in the body may cause oxidative stress such as cardiovascular, inflammation, cancer and aging. ${ }^{3,4}$ Owing to the diseases development by free-radicals, therefore extensive research need to be carried out based on plant with high antioxidant activity, in order to obtain new antioxidant from natural sources. One of the plant with high antioxidant activity are Annona squamosa L. (A. squamosa). ${ }^{5}$

The A. squamosa are family Annonaceae that was reported with 130 genus and almost 2500 species, ${ }^{6}$ where it can be found in tropical climate of Africa, Australia, South America and Indonesia for food consumption and traditional herbs. A. squamosa has been used to to treat diarrhea, influenza, cough, colon infection and the leaves was used as wound treatment. ${ }^{7,8}$ Besides, A. squamosa can be used for other food processing, ${ }^{9}$ juice, candy and sweets. ${ }^{10}$ Research on A. squamosa has been carried out based on its leaf, bark, roots, fruits and seeds, where A. squamosa reported to demonstrate an antioxidant, anticancer, antidiabetic, antihypertension, hepatoprotective, antiparasitic, antimalaria, insecticide and antimicrobes. ${ }^{10}$ The secondary metabolite of $A$. squamosa extracts contain several components such as saponin, alkaloid, coumarin, terpenoid, tannin, phenol and flavonoid. ${ }^{11}$ The secondary metabolite is potential as antioxidant, which containing phenolic groups. Recently, methanolic extract of $A$. squamosa demonstrate antioxidant activity of $135.2 \mathrm{mg} / \mathrm{mL}$ from fruits pulp source, ${ }^{12} 51 \pm 1.6 \mu \mathrm{g} / \mathrm{ml}$ from leaves based on DPPH results. ${ }^{8}$ In addition, Al-Nemari et al. (2020) reported that methanolic extract of A. squamosa leaves contain sesquiterpenes, diterpene alcohol, triterpene and ketone. However, most of the component are sesquiterpenes hydrocarbon.

Based on the above reports, it is interesting to investigate the separation of the compound via thinlayer chromatography (TLC) to further investigate the antioxidant activity of A. squamosa leaves extract. Therefore, in this work, the subfractions of the extract was further analyzed using GC-MS to identify the phytochemical compound. We found that an compound of 4,4'-((p-phenylene)diisopropylidene) diphenol was identified as Bisphenol $\mathrm{P}$ as phenolic group in the extracts.

\section{MATERIALS AND METHODS}

\section{Sample preparation}

A. squamosa leaf (ASL) was obtained from Syiah Kuala, Darussalam, Aceh-Indonesia at coordinate of latitude 5.576020 and longitude 95.380189 . The sample was clean with flow of tap water to remove impurities, dried and grinded into powder form with yield of $850 \mathrm{~g}$. The powder was macerated using methanol solution (70\%, Merck) for $24 \mathrm{~h}$ at room temperature. The filtrate was concentrate using rotary evaporator and partitioned with $\mathrm{n}$-hexane (99\%, Merck), followed by ethyl acetate (99\%, Merck) and was kept in cold refrigerator for further characterization. 


\section{Sample characterizations}

Subsequently, DPPH assay was used to determine antioxidant activity of ASL extract based on previous method..$^{13} 1 \mathrm{~mL}$ of $0.4 \mathrm{mM} \mathrm{DPPH}$ was dropped into various concentration of ASL methanol extract namely $6.25,12.5,25,50$ and $100 \mathrm{ppm}$ solution $(4 \mathrm{~mL})$. The solution was homogenized with vortex mixer and incubate for $30 \mathrm{~min}$ at $37^{\circ} \mathrm{C}$. The absorbance at $517 \mathrm{~nm}$ was recorded using UV-Vis spectrophotometer, where each concentration of ASL was recorded by triplicate to obtained $\mathrm{IC}_{50}$ value. As comparison, ascorbic acid was used as reference. In order to separate the non-volatile mixture, thin layer chromatography was carried out. ASL ethyl acetate extract about $3.03 \mathrm{~g}$ was fractionated using silica gel coloumn chromatography and $n$-hexane as liquid phase with gradient elution. Each fraction obtained using TLC with ratio n-hexane and ethyl acetate $(2: 8)$. The resulting fraction with similar pattern was combined with subfractioned to determine the antioxidant activity according to above procedure. Furthermore, the identification of ethyl acetate and its subfraction extract was performed to observed the phytochemical screening such as alkaloid, flavonoid, saponin, steroid, terpenoid dan phenolic according to Harborne methods. ${ }^{14}$ To understand the phytochemical compound contain in ASL extract, GCMS (Thermo Scientific). The non-polar colomn with He carrier gas was injected and the measurement temperature of $250{ }^{\circ} \mathrm{C}$ for $68.54 \mathrm{~min}$.

\section{RESULTS AND DISCUSSIONS}

Antioxidant activity was carried out using DPPH method with various concentration. Several concentration namely $6.25,12.5,25,50$ and 100 ppm of ASL extract, meanwhile 3, 9, 12 and 15 ppm of ascorbic acid were prepared. The antioxidant activity of ASL extract was obtained from $\mathrm{IC}_{50}$ value as function of concentration. The antioxidant activity of A. squamosal can be refer to Table 1 .

Based on Table 1, the antioxidant activity of ASM is higher than that ASE, ASH and Residual with following sequence from highest to lowest namely ASM > ASE > Residual $>$ ASH, where ASE IC50 is closed to ascorbic acid and therefore further used for isolation process.

\section{TLC analysis}

TLC results show that 181 fraction in total with each fraction was monitored based on similar stain marker for each fraction. Elution of fraction 1-180 as shown in Figure 1.

Stain marker for each similar fractions was combine into another subfraction and divided into 4 subfraction namely, ASE 1 (1-75), ASE 2 (76-85), ASE 3 (86-135) and ASE 4 (136-181). The subfraction for TLC was carried out with similar result and ASE 1-4 fraction was observed in Figure 2.

Table 1. Antioxidant activity of A. squamosa leaf extracts.

\begin{tabular}{|cc|}
\hline Sample & Nilai I $_{50}(\mathrm{ppm})$ \\
\hline ASM & 6.87 \\
ASH & 169.99 \\
ASE & 31.55 \\
Residual & 44.75 \\
Ascorbic acid & 3.03 \\
\hline
\end{tabular}

Table 2. ASE subfraction and its mass with $\mathrm{IC}_{50}$ value.

\begin{tabular}{cccc}
\hline Fraction & Subfraction & $\begin{array}{c}\text { Fraction mass } \\
(\mathrm{mg})\end{array}$ & $\begin{array}{c}\mathrm{IC}_{50} \\
(\mathrm{ppm})\end{array}$ \\
\hline ASE 1 & $1-75$ & 348.5 & 120.93 \\
ASE 2 & $76-85$ & 502.5 & 139.28 \\
ASE 3 & $86-135$ & 456.5 & 79.11 \\
ASE 4 & $136-181$ & 347.5 & 108.02 \\
Ascorbic acid & - & - & 4.07 \\
\hline
\end{tabular}

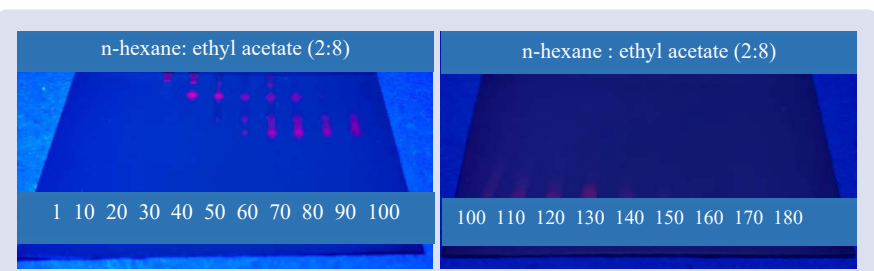

Figure 1. Elution fraction of ASE from fraction 1- 180 visualized under UV lamp $365 \mathrm{~nm}$.

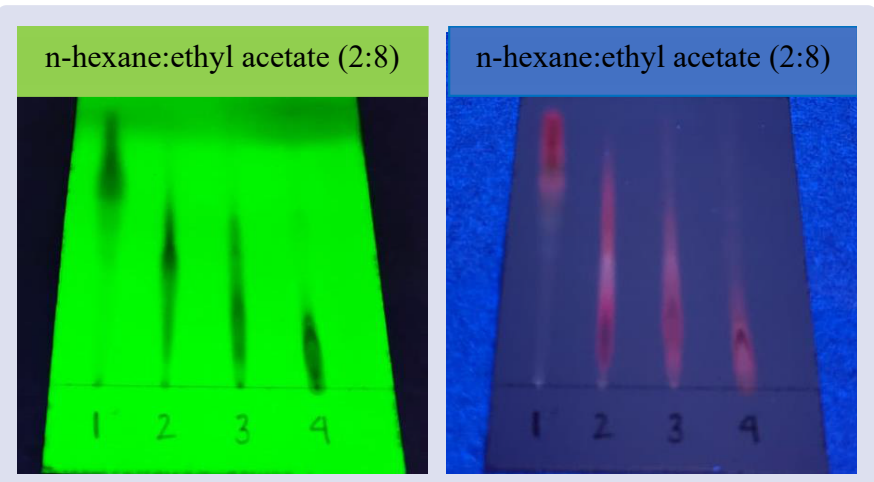

Figure 2. TLC subfraction from 1-4 visualized under UV 254 and $365 \mathrm{~nm}$.

Stain marker was obtained from TLC for four different subfractions of ASE indicates there is insignificant process due to the mixed compound, where suitable eluent was necessary to determine antioxidant activity and identification of phytochemical compound.

\section{Antioxidant activity of ASE extract}

Based on the DPPH method, the IC50 value of each ASE subfraction was obtained as shown in Table 4. Subfraction ASE-3 exhibit highest IC50 among other subfraction, which implying that antioxidant activity weaker compared to that ethyl acetate extracts. Lower antioxidant activity can be explained due to the functional group of ethyl acetate extract accepting a hydrogen atom to DPPH free radicals scavenging. In addition, the synergic effect if 2 compounds or more can gives beneficial with higher antioxidant activity if compared to prior subfraction using TLC. Accordingly, the phytochemical compound of ASE and its subfractions was determined as shown in Table 3 for alkaloid, flavonoid, saponin, terpenoid, steroid dan phenolic, where + and - represents with and without secondary metabolites, respectively.

The phytochemical results indicates that all subfractions contained alkaloid with Dragendorff and Mayer reagent. Besides, terpenoid, steroid and phenolic were observed without the presence of flavonoid and saponin. Recently, phytochemical compound of A. squamosa was investigated, ${ }^{15}, 16$ which contain phenolic, flavonoid, sulfated polysaccharide, tannins, and triterpenoids. Besides, A. squamosa chloroform extract contained steroid, terpenoid and phenolic compound, where chloroform with similar solvent polarity (semipolar) with ethyl acetate. ${ }^{17}$ Accordingly, the differences in secondary metabolites found in different extract was mainly due to the different in geography, climate, soil condition and age of A. squamosa plant.

The phytochemical compound contain in ASE-3 subfraction was identified using GC-MS and 19 phytochemical compounds were identified. The highest compound was patchouli alcohol, azulene, seychellene, $\alpha$-Guaiene and 1H-3a,7-Methanoazulene,2,3,6,7,8,8ahexahydro-1,4,9,9-tetramethyl-,(1a,3aa,7a,8aß) with concentration of 27.59, 11.84, 9.68, 8.72 and 8.30\%, respectively as shown in Figure 3.

The phytochemical compound in subfraction ASE-3 based on GC-MS analysis was shown in Table 4. 


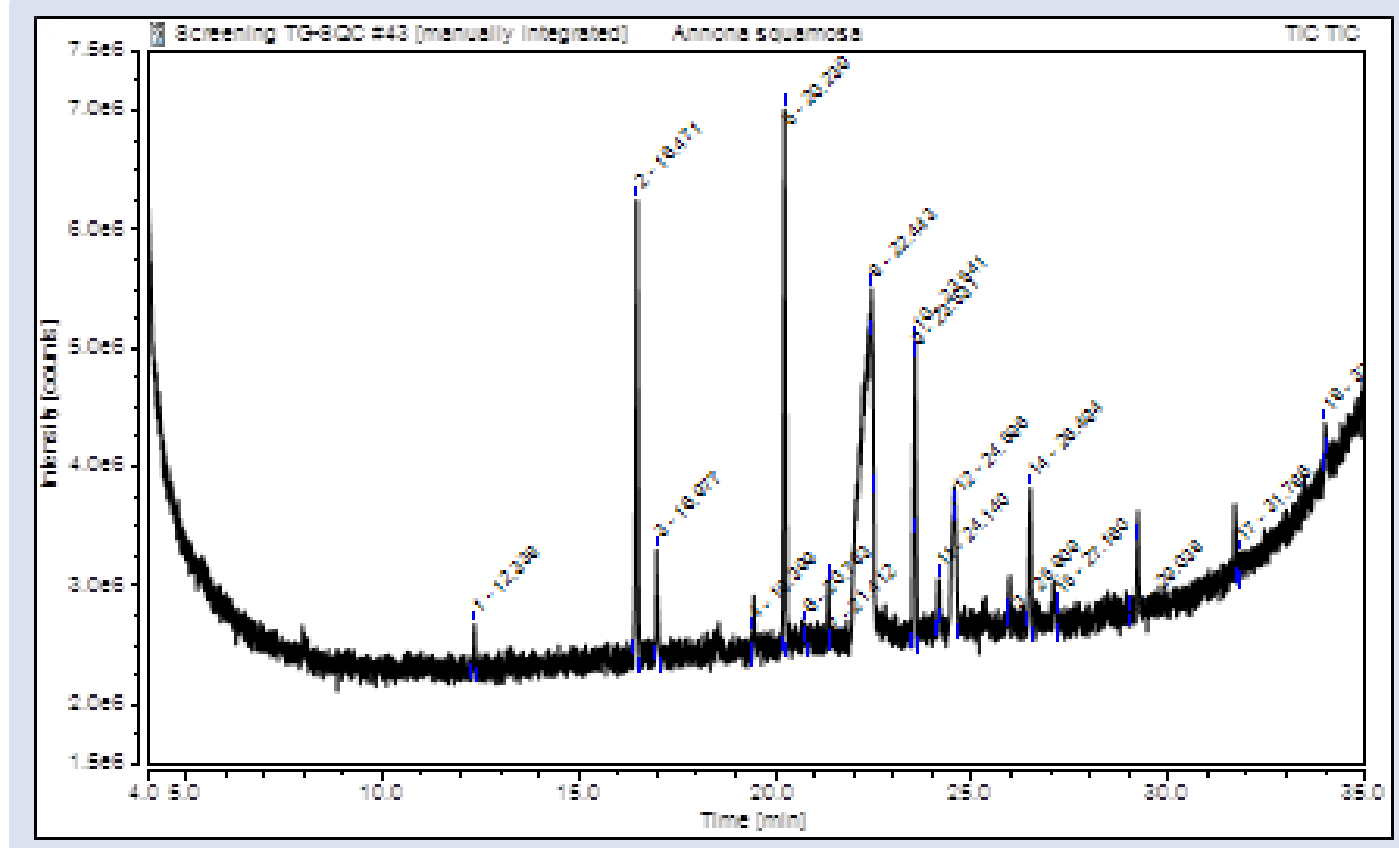

Figure 3. GC-MS spectrum of ASE-3 subfractions.

Table 3. Phytochemical screening of ASE and its subfractions.

\begin{tabular}{|c|c|c|c|c|c|c|c|c|}
\hline \multirow{2}{*}{ Sample } & \multicolumn{3}{|c|}{ Alkaloid } & \multirow{2}{*}{ Flavonoid } & \multirow{2}{*}{ Saponin } & \multirow{2}{*}{ Terpenoid } & \multirow{2}{*}{ Steroid } & \multirow{2}{*}{ Phenolic } \\
\hline & Mayer & Dragendorff & Wagner & & & & & \\
\hline ASE & - & + & + & - & - & + & + & + \\
\hline ASE 1 & - & + & + & - & - & + & + & + \\
\hline ASE 2 & - & + & + & - & - & + & + & + \\
\hline ASE 3 & - & + & + & - & - & + & + & + \\
\hline ASE 4 & - & + & + & - & - & + & + & + \\
\hline
\end{tabular}

Table 4. Relative percentage of the compounds detected in ASE-3 subfraction by GC-MS.

\begin{tabular}{|c|c|c|c|c|}
\hline No. & Compound Name & $\begin{array}{l}\text { Retention time } \\
\text { (min) }\end{array}$ & Peak area (\%) & $\begin{array}{l}\text { Similarity Index } \\
(\%)\end{array}$ \\
\hline 1 & Cyclohexasiloxane, dodecamethyl- & 12.338 & 2.44 & 65 \\
\hline 2 & Cycloheptasiloxane, tetradecamethyl- & 16.471 & 22.39 & 73 \\
\hline 3 & Dodecanoic acid, methyl ester & 16.977 & 5.66 & 68 \\
\hline 4 & $\begin{array}{l}\text { 2-Pyrazolin-5-ol, 3-trifluoromethyl-5-(3-pyridyl)-1-(2- } \\
\text { pyridylcarbonyl)- }\end{array}$ & 19.399 & 0.12 & 37 \\
\hline 5 & Cyclooctasiloxane, hexadecamethyl- & 20.239 & 27.43 & 82 \\
\hline 6 & syn-Retinal methoxime & 20.783 & 0.30 & 43 \\
\hline 7 & Methyl glycocholate, 3TMS derivative & 21.412 & 0.91 & 37 \\
\hline 8 & 4,4'-((p-Phenylene) diisopropylidene) diphenol & 22.443 & 5.94 & 52 \\
\hline 9 & Cyclononasiloxane, octadecamethyl- & 23.531 & 0.75 & 79 \\
\hline 10 & Cyclononasiloxane, octadecamethyl- & 23.541 & 16.60 & 79 \\
\hline 11 & Phthalic acid, isobutyl 2-methylpent-3-yl ester & 24.140 & 1.39 & 59 \\
\hline 12 & $\begin{array}{l}6,8 \text { - Diflu oro- } 2,2,4,4,6,7,7,8,9,9 \text { - decamethyl- } \\
{[1,3,5,2,4,6,7,8,9] \text { trioxahexasilonane }}\end{array}$ & 24.596 & 0.66 & 47 \\
\hline 13 & $\begin{array}{l}\text { 2-Naphthalenecarboxylic acid, } 4,4^{\prime}-\text { methylenebis[3- } \\
\text { methoxy- }\end{array}$ & 25.909 & 0.16 & 39 \\
\hline 14 & $\begin{array}{l}\text { Octasiloxane, } \\
\text { hexadecamethyl- }\end{array} \quad 1,1,3,3,5,5,7,7,9,9,11,11,13,13,15,15-$ & 26.494 & 8.16 & 67 \\
\hline 15 & 2-Myristynoyl-glycinamide & 27.160 & 0.15 & 37 \\
\hline 16 & 4-tert-Octylphenol, TMS derivative & 29.038 & 5.31 & 42 \\
\hline 17 & Silicic acid, diethyl bis(trimethylsilyl) ester & 31.786 & 0.59 & 56 \\
\hline 18 & $\begin{array}{l}\text { Tricyclo[4.2.1.0(2,5)]non-7-ene, } \\
\text { di(tris(trimethylsilyloxy)silyl)- }\end{array}$ & 33.990 & 1.00 & 57 \\
\hline 19 & Cyclotrisiloxane, hexamethyl- & 35.530 & 0.05 & 64 \\
\hline
\end{tabular}




\section{REFERENCES}

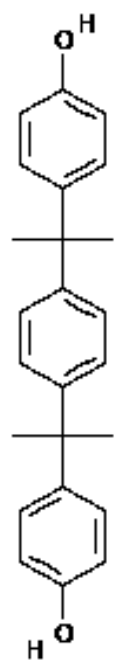

Figure 4. Chemical structure of 4,4'-((p-phenylene)diisopropylidene) diphenol.

The natural compound contain ASE subfraction 3 such as dodecanoic acid, methyl ester; 2-pyrazolin-5-ol, 3-trifluoromethyl-5-(3-pyridyl)1-(2-pyridylcarbonyl)-, syn-Retinal methoxime, phthalic acid, isobutyl 2-methylpent-3-yl ester, 2-Naphthalenecarboxylic acid, 4,4'-((p-Phenylene)diisopropylidene) diphenol and 2-myristynoylglycinamide. Meanwhile, 4,4'-((p-Phenylene)diisopropylidene) diphenol is a compound with concentration of $5.94 \%$, which contain antioxidant activity and the chemical structure was shown in Figure 4.

Chemical structure of $4,4^{\prime}-((p-p h e n y l e n e)$ diisopropylidene $)$ diphenol is considered as phenolic group with two functional group and molecular formula of $\mathrm{C}_{24} \mathrm{H}_{26} \mathrm{O}_{2}$ or so called Bisphenol $\mathrm{P}$ that was used as plastics and can food packaging. Moreover, bisphenol was commonly used to prevent the corrosion in metal. ${ }^{18}$ Several isomer of bisphenol namely bisphenol B, F, P, S and Z. Based on the molecular structure, the presence of bisphenol functional group may cause reaction of DPPH radical with hydrogen donor or electron accepting, thus leading to the enhancement of scavenging activity of phenolic.

\section{CONCLUSIONS}

In summary, A. squamosa leaf extracts and the identification of phytochemical compound of A. squamosa subfractions via TLC method were investigated. The antioxidant activity of A. squamosa leaf extracts based on DPPH scavenging activity such as ASM, ASE, residual and ASH demonstrate IC50 values of $6.79,31.50,44.70$ and $170.10 \mathrm{ppm}$, respectively. Furthermore, the subfraction using TLC method with lowest IC50 of ASE-3 compared to ASE1,2 and 4. Based on GC-MS analysis 4,4'-((p-Phenylene)diisopropylidene) diphenol, dodecanoic acid, methyl ester and phthalic acid, isobutyl 2-methylpent-3-yl ester with concentration of 5.94, 5.66 and $1.39 \%$, respectively. However, further investigation is required to determine the active compound of antioxidant and structural elucidation to obtain the active antioxidant structure.

\section{ACKNOWLEDGEMENT}

The authors would like to thanks Universitas Syiah Kuala with Hibah Penelitian to conduct this research.

\section{CONFLICTS OF INTEREST}

None.
1. Hasan F, Khachatryan L, Lomnicki S. Comparative studies of environmentally persistent free radicals on total particulate matter collected from electronic and tobacco cigarettes. Environmental science \& technology. 2020;54(9):5710-8. doi: https://doi. org/10.1021/acs.est.0c00351.

2. Suryadinata RV, Wirjatmadi B, Lorensia A. The time pattern of selenomethionine administration in preventing free radicals due to exposure to electric cigarette smoke. Journal of Public Health Research. 2021;10(2). doi: https://doi.org/10.4081/jphr.2021.2232.

3. Dhalaria R, Verma R, Kumar D, Puri S, Tapwal A, Kumar V, et al Bioactive compounds of edible fruits with their anti-aging properties: A comprehensive review to prolong human life. Antioxidants. 2020;9(11):1123. doi: https://doi.org/10.3390/antiox9111123.

4. Mercurio V, Cuomo A, Cadeddu Dessalvi C, Deidda M, Di Lisi D, Novo G, et al. Redox imbalances in ageing and metabolic alterations: implications in cancer and cardiac diseases. an overview from the working group of cardiotoxicity and cardioprotection of the Italian society of cardiology (SIC). Antioxidants. 2020;9(7):641. doi: https:// doi.org/10.3390/antiox9070641

5. Zahid M, Arif M, Rahman MA, Singh K, Mujahid M. Solvent extraction and gas chromatography-mass spectrometry analysis of Annona squamosa L. seeds for determination of bioactives, fatty acid/fatty oil composition, and antioxidant activity. Journal of dietary supplements. 2018;15(5):613-23. doi: https://doi.org/10.1080/19390211.2017.1366 388.

6. Xue B, Tan Y-H, Thomas DC, Chaowasku T, Hou X-L, Saunders RM. A new Annonaceae genus, Wuodendron, provides support for a post-boreotropical origin of the Asian-Neotropical disjunction in the tribe Miliuseae. Taxon. 2018;67(2):250-66. doi: https://doi. org/10.12705/672.2.

7. Dholvitayakhun A, Trachoo N, Sakee U, Cushnie TT. Potential applications for Annona squamosa leaf extract in the treatment and prevention of foodborne bacterial disease. Natural product communications. 2013;8(3):1934578X1300800327. doi: https://doi. org/10.1177/1934578X1300800327.

8. Al-Nemari R, Al-Senaidy A, Semlali A, Ismael M, Badjah-Hadj-Ahmed AY, Bacha AB. GC-MS profiling and assessment of antioxidant, antibacterial, and anticancer properties of extracts of Annona squamosa L. leaves. BMC Complementary Medicine and Therapies. 2020;20(1):1-14. doi: https://doi.org/10.1186/s12906-020-03029-9.

9. Souza FTC, Santos ER, Silva JdC, Valentim IB, Rabelo TCB, Andrade NRFd, et al. Production of nutritious flour from residue custard apple (Annona squamosa L.) for the development of new products. Journal of Food Quality. 2018:2018. doi: https://doi. org/10.1155/2018/5281035

10. Ma C, Chen Y, Chen J, Li X, Chen Y. A review on Annona squamosa L.: phytochemicals and biological activities. The American journal of Chinese medicine. 2017:45(05):933-64. doi: https://doi.org/10.1142/ S0192415X17500501

11. Nguyen $M$, Nguyen $V$, Le $V$, Trieu $L$, Lam $T$, Bui $L$, et al., editors. Assessment of preliminary phytochemical screening, polyphenol content, flavonoid content, and antioxidant activity of custard apple leaves (Annona squamosa Linn.). IOP Conference Series: Materials Science and Engineering; 2020: IOP Publishing.

12. Nandhakumar $E$, Indumathi P. In vitro antioxidant activities of methanol and aqueous extract of Annona squamosa (L.) fruit pulp. Journal of acupuncture and meridian studies. 2013;6(3):142-8. doi: https://doi.org/10.1016/j.jams.2012.09.002.

13. Sethi S, Joshi A, Arora B, Bhowmik A, Sharma R, Kumar P. Significance of FRAP, DPPH, and CUPRAC assays for antioxidant activity determination in apple fruit extracts. Eur Food Res Technol. 2020;246(3):591-8. 
14. Harborne J. Methods of plant analysis. Phytochemical methods: Springer; 1984. p. 1-36.

15. Shehata MG, Abu-Serie MM, Abd El-Aziz NM, El-Sohaimy SA. Nutritional, phytochemical, and in vitro anticancer potential of sugar apple (Annona squamosa) fruits. Scientific Reports. 2021;11(1):1-13. doi: https://doi.org/10.1038/s41598-021-85772-8.

16. Kumar M, Changan S, Tomar M, Prajapati U, Saurabh V, Hasan $M$, et al. Custard Apple (Annona squamosa L.) Leaves: Nutritional Composition, Phytochemical Profile, and Health-Promoting Biological Activities. Biomolecules. 2021;11(5):614. doi: https://doi.org/10.3390/ biom11050614.
17. Kalidindi N, Thimmaiah NV, Jagadeesh NV, Nandeep R, Swetha $\mathrm{S}$, Kalidindi B. Antifungal and antioxidant activities of organic and aqueous extracts of Annona squamosa Linn. leaves. Journal of food and drug analysis. 2015;23(4):795-802. doi: https://doi.org/10.1016/j. jfda.2015.04.012.

18. Manoj M, Kumaravel A, Mangalam R, Prabunathan P, Hariharan A, Alagar M. Exploration of high corrosion resistance property of less hazardous pyrazolidine-based benzoxazines in comparison with bisphenol-F derivatives. Journal of Coatings Technology and Research. 2020;17(4):921-35. doi: https://doi.org/10.1007/s11998019-00312-4.

\section{GRAPHICAL ABSTRACT}
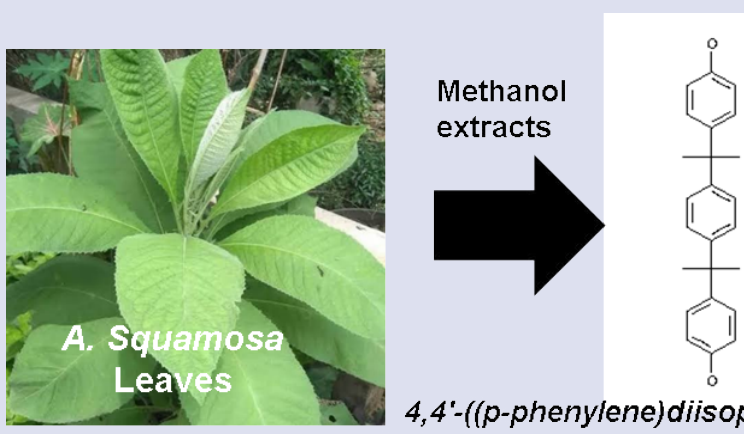

4,4'-((p-phenylene) diisopropylidene) diphenol

\section{ABOUT AUTHORS}

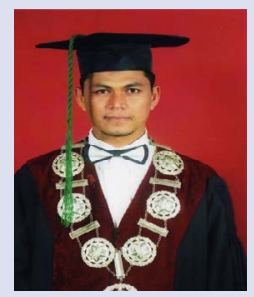

Dr. Mustanir is Professor at Universitas Syiah Kuala. He graduated at Institut Teknologi Sepuluh Nopember with a B.S. degree in Chemistry and obtained a PhD in Kyushu University in 2000 under supervision of Prof. Masaaki Mishima and Prof. Yuho Tsuno. Currently, active in teaching general chemistry, organic chemistry, natural products, and mechanism reaction organic chemistry for undergraduate and graduate levels at the Department of Chemistry, Faculty of Mathematics and Natural Sciences. Dr. Mustanir is also published many international journals in the field of organic chemistry and natural products.

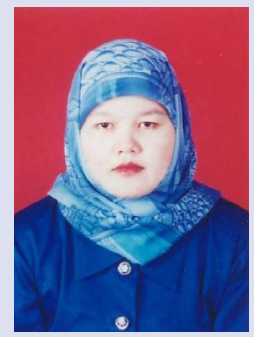

Dr. Binawati Ginting graduated has completed her PhD in Chemistry at Universitas of Sumatera Utara in 2015. Currently lecturer in department of Chemistry, Faculty of Mathematics and Natural Sciences, Universitas Syiah Kuala with more than 22 years of teaching experience both undergraduate and graduate degree, and main research expertise in the field tropical natural products extraction and its phythochemical compound for the application of antioxidant, anticancer, antibacterial, etc.

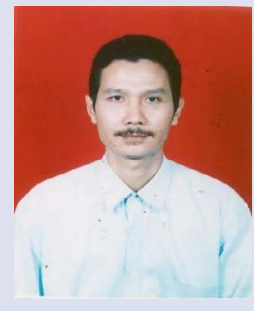

Dr. Nurdin currently active as lecturer in organic chemistry at Department of Chemistry, Faculty of Mathematics and Natural Sciences, Universitas Syiah Kuala, Banda Aceh, Indonesia. He obtained graduate degree in natural product chemistry at Universitas Padjajaran in Bandung, Indonesia in 1998. He completed his doctoral degree at Faculty of Science, Department of Chemistry, Universiti Malaya in 2007. His research field mainly focuses on natural product chemistry.

Cite this article: Mustanir, Nurdin, Ginting B. Antioxidant Activity and Phytochemical Identification of Annona Squamosa Leaves Methanolic Extracts. Pharmacogn J. 2021;13(6)Suppl: 1746-1750. 